\title{
ESTUDOS ESLAVOS NO BRASIL: CONSTITUIÇÃO DE UMA ÁREA
}

\section{Slavic Studies in Brazil: The Constitution of an Area}

\author{
Milan PUH \\ Universidade de São Paulo \\ milan.puh1@gmail.com \\ https://orcid.org/0000-0002-3231-806X
}

\begin{abstract}
RESUMO: Os estudos eslavos são uma área de conhecimento ainda pouco desenvolvida no Brasil, com produções pontuais que oferecem um estado da arte sobre a área, sua história e suas principais características. Ao mesmo tempo, vemos que existe um interesse crescente em se estudar assuntos ligados ao que se considera mundo eslavo, com o aumento de convênios acadêmicos, eventos, instituições ecursos, bemcomopesquisas em diferentes disciplinas científicas. Neste artigo, apresentaremos um panorama acerca dos ambientes onde se constrói conhecimento sobre o mundo eslavo no Brasil, aventando uma proposta de disciplinarização, o que significa delimitar e definir as características que possibilitariam a constituição do campo científico - estudos eslavos. O objetivo é mostrar as perspectivas históricas e institucionais de articulação de diferentes entidades e organizações que se dedicam ao mundo eslavo para que se possa pensar em diálogos que poderão constituir esta área de estudos. Igualmente, procuraremos definir as diversas perspectivas teóricas e metodológicas que as instituições apresentam, visando "desocultar" e "desorientalizar" a produção de conhecimento dessa área. Desses dois modos, almejamos oferecer um balanço que poderá servir como um norte para criação de novas propostas (inter)nacionais e locais de integração e colaboração de pesquisadores dos estudos eslavos. PALAVRAS-CHAVE: Estudos eslavos; Disciplinarização; Brasil; Mundo Eslavo.
\end{abstract}

ABSTRACT: Slavic studies is an area of knowledge still
underdeveloped in Brazil, with occasional productions that offer a state
of the art about the area, its history and its current trends. At the same
time, we see that there is a growing interest in studying topics related
to what is considered as the Slavic world, with the increase in academic
agreements, events, institutions and courses, as well as research in
different scientific disciplines. In this article, we will present an overview
of the spaces where knowledge is made concerning the Slavic world
in Brazil, putting forward a proposal of scientific disciplinarization, 
which means delimiting and defining the characteristics that would make possible the constitution of the scientific field - Slavic studies. The objective is to show the historical and institutional perspectives of articulation of different entities and organizations that are related to the Slavic world so that one can think of dialogues that can constitute this area of studies. Likewise, we will try to define the various theoretical and methodological perspectives that the institutions present, aiming at "unhiding" and "disorientalization" of the production of knowledge in this area. In these two ways, we aim to offer a balance that could serve as a guide for of new (inter)national e local proposals of integration and collaboration between researchers in Slavic studies. KEYWORDS: Slavic Studies, Disciplinarization; Brasil; Slavic world.

SAŽETAK: Slavistika je znanstveno područje koje u Brazilu još uvijek nije dovoljno razvijeno, tek s ponekim preglednim znanstvenim koji donosi novija saznanja o području, njegovoj povijesti i glavnim značajkama. Istodobno, primjetno je da postoji sve veće zanimanje za izučavanje tema vezanih s onim što se smatra slavenskim svijetom, s porastom akademskih sporazuma, događaja, institucija i studija, kao i istraživanja u različitim znanstvenim disciplinama. U ovom ćemo članku predstaviti pregled područja u kojima se stvara znanje o Slavenima u Brazilu, iznoseći prijedloge za njezinu disciplinarizaciju, što znači razgraničenje i određivanje karakteristika koje bi omogućile konstituciju znanstvenog područja - Slavistike. Cilj je prikazati povijesnu i institucionalnu perspektivu artikulacije različitih institucija i organizacija posvećenih slavenskom svijetu kako bi se mogle navesti poveznice koje sačinjavaju ovo znanstveno područje. Isto tako, definirat ćemo različite teorijske i metodološke perspektive koje su razvidne iz institucionalnog djelovanja, imajući kao cilj "razotkrivanje" i "dezorijentalizaciju" znanstvenog stvaralaštva ovog područja. Kroz ove dvije metode želimo ponuditi pregled koja bi mogao poslužiti kao smjerokaz za stvaranje novih (inter) nacionalnih i lokalnih prijedloga za integraciju i suradnju Slavista. KLJUČNE RIJEČI: Slavistika; Disciplinarizacija; Brazil; Slavenski svijet. 


\section{INTRODUÇÃO}

Neste artigo apresentaremos os primeiros resultados do mapeamento sobre estudos eslavos obtidos no âmbito da pesquisa de pós-doutoramento ${ }^{1}$, junto ao Programa de Pós-graduação em Educação (PPG) da Universidade do Centro-Oeste do Paraná (UNICENTRO), acompanhados de uma discussão metodológica sobre possíveis modos de se realizar e refletir sobre esse tipo de estudo. É preciso reconhecer o aumento e a aceleração da inclusão do elemento eslavo no escopo da atuação da universidade brasileira, realizado nos últimos anos por meio das parcerias com as universidades de diversos países eslavos: Rússia, República Tcheca, Polônia, Ucrânia, Croácia, Sérvia, Montenegro etc., que envolvem convênios e intercâmbios para os universitários e ampliação de oferta de outras línguas eslavas que não somente o russo, dentre outras oportunidades.

Por conta da aproximação neste estado de arte sobre uma área de conhecimento, tornou-se possível identificar instâncias e momentos a serem revisitados, que possibilitaria a constituição de novos modos de pensar e articular as línguas e culturas eslavas no Brasil, e também ajudaria na criação de maneiras de colaboração com outras universidades (inter) nacionais. Por isso, consideramos importante sistematizar, pensar e atuar em atividades de ensino e pesquisa complementares ao que já está sendo realizado, reforçando uma articulação nacional e pensando simultaneamente nas metodologias a serem empregadas para chegar a tal estudo, por ser algo ainda pouco explorado no Brasil.

Assim sendo, a proposta deste artigo é a realização de um estudo exploratório e descritivo de espaços em que se produz e divulga conhecimento à respeito dos eslavos, propondo uma atualização acerca de como a área pode ser percebida pelos seus pesquisadores e educadores, como também do próprio mundo eslavo, e visando também alcançar um melhor relacionamento com outras instituições de ensino na articulação de suas diversas áreas do conhecimento. Trabalharemos também na necessidade de aprimoramento das metodologias de pesquisa para (auto)análise da produção, bem como a da área de estudos linguísticos e educacionais; e na mobilização de conhecimentos das políticas e suas elaborações futuras em todos os níveis de atuação - pesquisa, ensino, extensão.

E por fim, nos preocuparemos em registrar as ideias, concepções e questões que surgiram ao longo da realização da pesquisa, pois em uma época marcada pelo

\footnotetext{
${ }^{1}$ O presente trabalho foi realizado com apoio da Coordenação de Aperfeiçoamento de Pessoal de Nível Superior - Brasil (CAPES) - Programa Nacional de Pós-Doutorado - PNPD, Edital n.005/2018 - PPGE/UNICENTRO.
} 
produtivismo e comercialização do conhecimento, criar uma autorreflexão nos parece um elemento fortalecedor da cultura universitária, da diversificação e da capacidade da universidade pública de sustentar o seu trabalho através do ensino e pesquisa.

\section{METODOLOGIA: PRESSUPOSTOS PARA UMA DISCIPLINARIZAÇÃO}

Em se tratando de um assunto ou uma área até agora pouco investigada, este artigo é definido como parte de um estudo exploratório. Esse costuma ser o primeiro passo a ser feito em uma pesquisa que se propõe estabelecer uma visão mais abrangente sobre o tema a ser abordado, o que é o caso de estudos eslavos. Como afirma Gil (1987), o estudo exploratório visa aprimorar as ideias e concepções, bem como identificar algumas histórias e tendências que existem, e que ainda não foram nomeadas. Portanto, esse tipo de estudo, segundo Triviños (1987), descreve os fatos e fenômenos de determinada realidade. Como falamos nas considerações iniciais, existe uma intensa troca, cada vez mais forte, entre os países eslavos e o Brasil, um fenômeno ainda recente em termos de mapeamento, classificação e análise por parte da universidade.

Reforçando mais ainda a nossa afirmação - não existe uma definição do que seriam estudos eslavo no Brasil, ou seja, não foi criada uma área de conhecimento que pudesse reunir os produtores de conhecimento com as suas produções e com os coletivos aos quais pertencem. Por isso seria preciso empregar um processo de disciplinarização que daria conta de criar uma demarcação e descrição que pudesse servir de base para futuras elaborações de projetos, parcerias e pesquisas. Não se trata somente de criar uma disciplina de conhecimento, mas de organizar os conhecimentos de acordo com a sua historicidade, memória da conjuntura teórica, como comentam Mariani e Medeiros (2013). Segundo as autoras, o processo de disciplinarização pressupõe a produção de saber, ou ainda, o estudo de mecanismos político-acadêmicos que participam na institucionalização do saber, pois "a compreensão das condições históricas que propiciam a emergência de uma disciplina é crucial para se desfazerem as evidência que deixam a transmissão da produção de conhecimento como discursos em sujeito“ (MARIANI; MEDEIROS, 2013, p.17). E ainda asseveram que "o conhecimento é produzido, é disciplinarizado e circula em condições histórico-enunciativas de produção bastante específicas, o que significa a inserção em políticas científicas e acadêmicas nacionais, e ainda, que indiretamente, internacionais" (MARIANI; MEDEIROS, 2013, p.17).

Aqui só queremos lembrar que o objetivo não é estabelecer um processo que resultaria em uma área de conhecimento específico "disciplinado" com fronteiras teórico- 
metodológico fechadas, com finalidade em si mesma. Como já comentado, trata-se de um estudo de cunho exploratório, que propõe fazer um panorama de estudos eslavos, descrevendo as principais instituições, cursos e indivíduos que contribuíram, ainda que não explicitamente, para o desenvolvimento de uma produção acadêmica de temáticas relacionadas ao mundo eslavo. A intenção é aproximar e potencializar novas pesquisas que possam se enquadrar ou extrapolar o que vem sendo produzido dentro da área de estudos eslavos, pois sem um entendimento do que acontece(u) não será possível planejar, sugerir e articular novas pesquisas e produções.

Portanto, aqui é importante nos perguntarmos: por que no Brasil parece nunca ter havido uma articulação nacional para que o conhecimento produzido fosse disciplinarizado em uma área de estudos, tal qual vemos para outras etnicidades: italiana, espanhola, japonesa, germânica etc.? E ainda, se houve, por que a sua divulgação e reconhecimento não está no mesmo patamar das demais?

Tais questionamentos são necessários aqui porque trazem efeitos para com a metodologia que empregamos na nossa pesquisa. É importante ressaltar que, pela incipiência da área de estudos, nos vimos obrigados a trabalhar com a ideia de lacunaridade de materiais e dados, que sempre prejudicam qualquer estudo científico, especialmente um de cunho exploratório e, parcialmente, descritivo. Porém, somos de opinião de que é necessário começar a produzir conhecimento sobre os estudos eslavos, proporcionando maior visibilidade às instituições, coletivos e indivíduos envolvidos. $\mathrm{E}$ essa preocupação científica e epistemológica na nossa visão pressupõe trabalhar com o conceito de desocultamento (étnico). Ele serve como o elemento metodológico que possibilitará revelar a existência de uma produção que ainda não recebeu esse nome, e que, em muitos casos, foi ocultado por diversos fatores histórico-sociais que não permitiram a disciplinarização de todos os envolvidos na constituição desse processo.

No Brasil, como afirmam Camargo e Puh (2020), é somente no começo do século 21 que se começa a trabalhar com a temática dos ocultamentos no que se refere a comunidades étnicas imigrantes, ainda que de modo incipiente. O desocultamento como conceitobase para a nossa pesquisa foi elaborado a partir do trabalho de Decol (2000), no qual é abordada a comunidade judaica proveniente da Europa Central-Oriental, principalmente da Polônia. O autor mostra que países faziam agrupamentos de diversas nacionalidades, os quais costumavam ocultar a diversidade do grupo em questão. Nós tomamos essa ideia e ampliamos para mostrar que há um ocultamento das etnias eslavas no Brasil, o que teve o mesmo efeito no ambiente acadêmico e na produção de conhecimento a respeito do que chamamos de estudos eslavos. 
Complementar e concomitante ao desocultamento, encontra-se o segundo conceito-base da nossa abordagem metodológica de exploração e descrição: a orientalização linguística, abordada e descrita por nós em um outro trabalho (PUH, 2020). Nesta publicação caracterizamos o que chamamos de procedimentos de orientalização, concomitante ao ocultamento no processo de disciplinarização da área de estudos eslavos, o qual acreditamos ser uma das chaves para o entendimento da formação de relações acadêmico-teóricas internacionais que a Universidade brasileira estabelece com o mundo eslavo, e mais, com os países considerados não-ocidentais. Dado o contexto de articulações acadêmicos e profissionais nos quais as línguas eslavas foram se inserindo no Brasil a partir do anos 1960, conforme elaborado em trabalhos de Bernardini (1994) e Diniz (1994), percebe-se a existência de uma pluralidade de culturas e países envolvidos nesse processo, bem como uma transversalidade de suas abordagens em cursos e centros universitários, e grupos de pesquisa.

Consideramos que mais estudos sobre os porquês da inserção, relativamente comum, do mundo eslavo no mundo oriental contribuiria para uma renovação de práticas de ensinamento e conhecimento a respeito de diversas línguas (eslavas ou não) no Brasil. Entendemos que, quanto mais uma ideia é repetida, mais ela torna-se presente e reforça a imagem já existente daquilo que se fala; no caso das línguas orientais ou orientalizadas, significa distanciá-las das chamadas ocidentais. Portanto, ter uma clareza do que significa “oriental” na Universidade e sua aplicação na definição de línguas e os modos de ensinálas, pode nos ajudar a entendermos as razões de possíveis ocultamentos das línguas eslavas. E vice-versa, uma vez que a falta de visibilidade destas línguas e culturas, e suas contribuições e produções brasileiras, faz com que elas sejam orientalizadas, prejudicando a sua expansão institucional e inviabilizando o seu desenvolvimento.

Além disso, como notamos em Diniz (1994, p. 471-472), a compreensão do estado de conhecimento sobre um tema, em determinado momento, é necessária no processo de disciplinarização da ciência, a fim de que se ordene periodicamente o conjunto de informações e resultados já obtidos. Essa ordenação permitiria a indicação das possibilidades de integração de diferentes perspectivas, aparentemente autônomas, a identificação de duplicações ou contradições, e a determinação de lacunas e vieses ideológicos. Por isso, iniciamos com as explorações das instituições e seus principais atores, considerando que seja necessário fazer-se um panorama, ou seja, um estudo de arte descritivo com a intenção de proporcionar maior familiaridade com a problemática e criar um ambiente mais propício a futuras pesquisas.

E por fim, após termos feito um diagnóstico inicial das razões que nos levaram 
a tentar definir o campo dos estudos eslavos no Brasil, criando condições para a sua disciplinarização como uma área de conhecimento, precisamos ainda falar do nosso procedimento "desocultante" e "desorientalizante" no que se refere à constituição do corpus. No nível mais amplo, procuramos compreender o histórico social e institucional das Universidades brasileiras e seus cursos de graduação e pós-graduação, junto com suas propostas e históricos. Enfocamos, em seguida, o contexto institucional dos Núcleos e Centros, junto com as iniciativas em que há uma presença eslava, explorando as suas principais características, apesar da dificuldade de encontrar documentos e interlocutores. Essa dificuldade já é indicativa do processo de ocultamento macro-institucional e microindividual que não deixa rastros facilmente localizáveis, o que acaba sugerindo uma aparente baixa preocupação em produção de memórias documentais para fins de criação de histórias institucionais. Por isso, esse trabalho exploratório lançou mão das mais diversas fontes de informação, tais como: artigos científicos e jornalísticos, propostas de avaliação de programa de pós-graduação, sites de internet, publicações comemorativas, projetos político-pedagógicos e conversas com alguns dos agentes institucionais envolvidos com o mundo eslavo.

\section{ESTUDOS ESLAVOS NO BRASIL: CONSTITUIÇÃO DE UM CAMPO}

No mundo acadêmico brasileiro, a produção de conhecimento mais sistemática acerca do mundo eslavo, enquanto uma disciplina ou um campo de estudos, localiza-se apenas a partir dos anos 1960. Na época, o prof. Boris Schnaiderman funda o Curso de Graduação em Língua e Literatura Russas na Faculdade de Filosofia, Letras e Ciências Humanas na Universidade de São Paulo, inicialmente livre, porém oficialmente sendo reconhecido em 1963. Em 1994, o Programa de Pós-graduação em Literatura e Cultura Russa foi reconhecido pelas instâncias da própria Universidade de São Paulo, sendo que somente no começo dos 2000, o programa recebe o reconhecimento da Coordenação de Aperfeiçoamento de Pessoal de Nível Superior (CAPES): o mestrado em dezembro de 2001 e o doutorado em março de 2002.

A professora Bernardini, docente que acompanha o funcionamento do curso de Russo desde a sua criação, traz suas observações sobre os encaminhamentos da pesquisa numa perspectiva histórica, afirmando que:

Além dessas dez linhas de natureza eminentemente crítico-literária, ainda estão sendo implementadas pelos docentes do curso algumas pesquisas linguístico-gramaticais envolvendo o estudo de Metodologias 
de ensino de russo para brasileiros e a elaboração de uma Gramática comparada do russo e do português, dando ênfase particular à questão das estruturas verbais russas. Finalmente, em virtude de traduções realizadas, do credenciamento de semioticistas visitantes para ministrar cursos de pós-graduação e do desdobramento de cursos de extensão já ministrados, foi implementada uma linha de pesquisa abrangendo estudos sobre Semiótica da Cultura Russa, reunindo estudos semióticos de língua, literatura e cultura russa, tendo como modelo os estudos de Jakobson, Tinianov e demais representantes do formalismo russo, dos folcloristas russos Propp e Mielietinski e da assim chamada Escola de Tartu (BERNARDINI, 1994, p. 469-470).

Aqui vemos a preocupação em ampliar o escopo do programa que era predominantemente de natureza crítico-literária, mencionando pesquisas linguísticogramaticais que envolviam aspectos relacionados com a metodologia de ensino e elaboração gramática. Mas, acabou não constituindo uma linha de pesquisa, pois como vemos no memorial da Proposta do programa para a avaliação da CAPES de 2009, as linhas eram: 1) prosa russo-soviética; 2) semiótica da cultura; 3 ) teoria e crítica da literatura russa; 4) teoria, estética e crítica do teatro russo e soviético, indicando uma predominância de temas literários e tradutológicos. Essa tendência certamente pode ser entendida como o legado do fundador Boris Schnaiderman e dos docentes envolvidos no processo de constituição institucional do programa, o que é confirmado não somente pela autora acima citada, mas pelo memorial da própria proposta do programa enviada para uma das avaliações da CAPES em 2009. Nela, definem-se três eixos essenciais que constituíam o programa de pós-graduação, sendo esses: língua, literatura e cultura. A partir daí afirma-se que o programa de Literatura e Cultura Russa visava a:

1) formar profissionais qualificados nessa área de conhecimento para atender demandas da sociedade, principalmente no campo da tradução tanto de obras literárias, como crítico-científicas, permitindo a ampliação dos estudos russos no Brasil e a sua constante divulgação; 2) promover o ensino e a pesquisa no nosso campo de conhecimento, privilegiando os estudos da literatura, da teoria e da crítica literária russas, bem como os estudos da arte e da cultura russas; 3) habilitar o mestrando e o doutorando para a sua formação profissional nessa área de estudos e, sobretudo, promover uma formação intelectual crítica e criativa, que os capacite a atuar de forma eficaz no ensino, na tradução, na pesquisa acadêmica, em consultoria e em quaisquer atividades correlatas, por eles exercidas profissionalmente (UNIVERSIDADE DE SÃO PAULO, 2009, p. 2) 
Portanto, cria-se o único programa de pós-graduação dedicado a alguma língua eslava que pretendia formar profissionais que atuariam principalmente no campo da tradução, mas que foi fusionado em 2019 com outros três programas, a saber: Estudos Linguísticos Literários e Tradutológicos em Francês, Estudos Judaicos e Árabes e Estudos da Tradução, instituindo-se o programa de pós-graduação "Letras Estrangeiras e Tradução" (LETRA). Novamente, podemos perceber que o programa maior envolve diversas línguas estrangeiras, agrupadas a partir da sua ligação com a área de tradução, sendo esse o principal processo de disciplinarização de estudos russos no nível de pósgraduação na USP.

No que se refere ao curso de graduação, ele atualmente está enquadrado no Departamento de Letras Orientais, junto com as seguintes línguas: Árabe, Armênio, Chinês, Coreano, Hebraico e Japonês. Ou seja, o russo como representativo do eslavo encontra-se no mesmo grupo que outras línguas localizas fora da Europa ocidental, e com a exceção da Armênia, fora da Europa. Portanto, a sua institucionalização nesse nível fica vinculada ao mundo oriental, efetivando e/ou confirmando um processo que chamamos de orientalização em que línguas e culturas que não pertencem ao mundo ocidental, e mais especificamente, aos países hegemônicos da Europa e Norte da América, ficam inseridas e disciplinarizadas em um único grande grupo.

A situação parecida ocorre com o Departamento de Letras Orientais e Eslavas da Faculdade de Letras da Universidade Federal do Rio de Janeiro (UFRJ), que foi criado em 1968, com a criação do curso de Letras Português-Russo no Setor de Letras Russas no mesmo ano, seguido pelo Setor de Estudos Árabes (1969), Setor de Línguas e Literaturas Hebraicas (1971) e Setor de Letras Japonesas (1979), como afirma Barbosa (2007). A habilitação em licenciatura, ao contrário da USP, é realizada na própria Faculdade de Letras, mas no que se refere à produção de conhecimento e de formação de pesquisadores, é possível traçar paralelos entre as duas instituições. Sobre a pós-graduação na área do russo encontramos informações no artigo de Barbosa que traça o histórico institucional da pós-graduação na Faculdade de Letras. A autora fez uma abordagem dos documentos oficiais (decretos, leis, regulamentos) de todas as áreas e programas e, dentre outras coisas, traz dados para o nosso estudo exploratório-descritivo.

No regulamento de 1983, cria-se a área de Letras Orientais e Eslavas com russo, e isso foi possível pela alínea $b$, do artigo 2 que dizia que a pós-graduação tinha diferentes modalidades: aperfeiçoamento, especialização, treinamento profissional e atualização. A partir desse momento, começam a se oferecer cursos de pós-graduação latu sensu na modalidade "Especialização" para a área do russo que, conforme Barbosa (2007, p. 30), 
continua até hoje. Entrando mais especificamente na temática do oferecimento dessa modalidade, encontramos que foi oferecido o curso de "Literatura Russa" (BARBOSA, 2007, p. 30), fato que indica uma proposta mais voltada para a área de estudos literários, e possivelmente tradutológicos. Mas no regulamento de 1990, essa área não foi considerada pela CAPES como produtiva, uma vez que somente considerava as produções dos cursos stricto sensu, ocasionando na sua retirada dos programas de pós-graduação. Esse desenrolar de fatos institucionais novamente demonstra as inconstâncias e instabilidades de uma área de estudos eslavos dedicada à pesquisa na pós-graduação. No caso de ambas as instituições (USP e UFRJ), a afirmação da área de estudos eslavos passou por tentativas, mais ou menos bem sucedidas, de criar programas que não conseguiram se afirmar na lógica do produtivismo acadêmico brasileiro, impossibilitando a sua existência como áreas independentes, efetivando um ocultamento institucional. É importante notar que, a partir dos anos 1990, os programas de pós-graduação não refletem mais somente as atividades de ensino, mas os interesses dos grupos de pesquisa, algo que Barbosa (2007) identifica como mudanças gerais na pós-graduação brasileira.

Podemos observar que ambos cursos, isto é, áreas apresentam pontos em comum, no que se refere à sua disciplinarização tanto na graduação e na pós-graduação. $\mathrm{Na}$ nossa opinião, isso se deve ao processo de orientalização que acompanha a língua russa (institucional e culturalmente) no Brasil, que tem como um dos efeitos o seu ocultamento em outros programas de pós-graduação. Isso, por sua vez, faz com que não haja uma visibilidade maior da produção de conhecimento que certamente existe, dificultando futuros mapeamentos e análise, demandando, portanto, estratégias de localização e análise criativas e sensíveis a essa temática. E mais, nos chama para refletirmos sobre o conflito entre a orientalização das línguas eslavas e o produtivismo acadêmico ocidentalizado que parece dificultar a afirmação de estudos eslavos e seu crescimento nessas grandes, conhecidas e qualificadas universidades. Para começarmos a pensar estratégias que nos ajudarão a entender melhor esse assunto, é preciso pensar nos porquês dessa disciplinarização do mundo eslavo, ou melhor, de uma das suas línguas/culturas.

No entanto, essa não é a única possibilidade de disciplinarização de estudos eslavos, pois também existe o curso de língua e literatura polonesa no Departamento de Polonês, Alemão e Letras Clássicas (DEPAC) da Universidade Federal do Paraná, inserido, como veremos, em um outro contexto geopolítico e epistemológico. A sua criação acontece após um longo vácuo de aproximadamente 50 anos, iniciado com as políticas inibitivas do período do governo Vargas. Embora houvesse uma longa história de ensino eslavo étnico nesse estado, lembrando que no Sul do Brasil existiam mais de 300 escolas polonesas até 
1938, segundo Renk (2009), com as proibições que se iniciaram ainda nos anos 1930, a afirmação de estudos eslavos por meio de cursos e instituições de ensino e pesquisa foi demorada. Sendo assim, este curso foi criado recentemente, em 2009, fazendo parte inicialmente do Departamento de Letras Estrangeiras Modernas (DELEM), para em 2015 integrar o próprio DEPAC. Aqui uma língua eslava é vinculada à língua alemã e às línguas clássicas como grego e latim, permanecendo no contexto europeu. É interessante observar que o Departamento em que o curso se localiza, integra os Cursos de Graduação e Pós-Graduação em Letras da mesma universidade, ao lado do Departamento de Letras Estrangeiras Modernas (DELEM) e Departamento de Literatura e Linguística (DELLIN). O que pode se inferir disso é que essas duas línguas modernas: alemão e polonês não estão no mesmo grupo onde se encontram inglês, espanhol, francês, italiano e japonês, mas sim em um outro no qual estão as clássicas e a área de tradução. Não adentraremos aqui a abordagem institucional e as razões pelas quais isso aconteceu, porém deixamos evidenciada essa realidade, acrescentando o fato de que o curso da língua japonesa foi aprovado no mesmo ano que o polonês, mas permaneceu no DELEM.

Agora, a presença do polonês nessa universidade pode se explicar pela forte imigração de poloneses ao estado do Paraná, um fato que já traz outra concepção para a criação e manutenção de um espaço onde se ensina e estuda uma determinada parte do mundo eslavo. A língua polonesa, assim, fica posicionada ao lado da alemã na Europa Central, retirando de certo modo o seu caráter "orientalizado", mas deixando próximo de certo modo à área de tradução, embora essa não seja principal preocupação curso, conforme o seu Projeto Político Pedagógico de 2007. Vejamos o que diz a respeito do modelo inicial da habilitação única em polonês:

O modelo das novas habilitações de Curso de graduação em Letras que estamos apresentando pretende superar também uma lacuna presente em grande parte dos cursos de Letras existentes no Brasil, que é a sobrecarga de disciplinas obrigatórias de formação geral, ditas de núcleo ou tronco comum, em detrimento da formação específica na língua estrangeira, que acaba tendo pouco espaço na estrutura curricular e nas grades horárias dos cursos. No caso de línguas como a japonesa e a polonesa, que não pertencem ao conjunto das línguas mais conhecidas e difundidas entre nós, um número maior de disciplinas específicas é fundamental. (PROJETO POLÍTICO PEDAGÓGICO, 2007, p. 3)

Sustenta-se que o curso de polonês, por ser uma língua menos conhecida e difundida no Brasil, precisaria de uma estrutura curricular com menos disciplinas obrigatórias de formação geral, oferecendo mais condições que a formação do aluno 
se dê de modo mais incisivo no mundo das disciplinas específicas. Ainda se acrescenta que a meta da formação seja proficiência "na língua estrangeira e conhecimento cultural sólido que lhe permita exercer plenamente a atividade de professor, pesquisador, crítico literário, tradutor, intérprete, editor, redator, revisor de texto, roteirista, assessor cultural e outras funções correlatas" (PROJETO POLÍTICO PEDAGÓGICO, 2007, p. 4). As diversas atividades elencadas indicam justamente uma multiplicidade de formações e de possibilidades de exercer a profissão de graduado/graduada em língua e literatura polonesa, pressupondo, então, uma formação de uma proposta de estudos eslavos que chamaremos de amplificada. Ainda é relevante mencionar que o curso passou a ter a licenciatura única em 2009, para em 2019 ser reformulada sob o seguinte nome "Curso de Licenciatura em Letras Português e Polonês" como consta no Projeto Pedagógico, incorporando também a língua portuguesa no seu escopo. Neste documento, cita-se que o objetivo dessa inclusão era de "proporcionar integração entre os universos culturais brasileiro e polonês" (PROJETO PEDAGÓGICO, 2019, p. 6), acrescentando ainda que o licenciado atuaria como "disseminador da língua portuguesa e das literaturas lusófonas no universo acadêmico polonês, em diversas oportunidades de intercâmbios" (PROJETO PEDAGÓGICO, 2019, p. 6-7). Essa modificação indica uma outra visão sobre o trabalho de um profissional em Letras formado nesta área, imaginando um trabalho mais intercultural na produção de conhecimento, como diz o próprio documento. Ainda cabe dizer que a reformulação se baseava num objetivo que, para além de reconhecer e fortalecer a presença polonesa no estado e no Brasil, propunha a expansão da "presença da Eslavística em cursos de graduação oferecidos por Instituições de Ensino Superior em nosso continente" (PROJETO PEDAGÓGICO, 2019, p. 4), explicitando uma preocupação maior com a área de línguas e culturas eslavas.

Uma proposta um pouco diferente pode ser encontrada no segundo curso do polonês ainda não pleno (sem o estatuto de habilitação ou licenciatura), aberto em 2011, por meio de uma resolução da Reitoria da Universidade de Brasília, mas idealizado e coordenado por Henryk Siewierski. Trata-se da Cátedra Cyprian Norwid no Instituto de Letras do Departamento de Teoria Literária e Literatura que recebe apoio não somente da Universidade de Brasília, mas também da Embaixada da Polônia no Brasil, de acordo com Malczewski (sem data). Nesse caso, abre-se uma cátedra específica para uma língua eslava em um instituto cujas preocupações podemos definir como de relações internacionais e acadêmicas, culturais e educacionais. Vejamos quais são os objetivos estipulados para a atuação dessa cátedra, segundo consta no site da Cátedra: a) Criar condições para garantir a continuidade e o desenvolvimento do ensino de língua e cultura 
polonesa como disciplinas optativas oferecidas pelo Instituto de Letras; b) Promover o diálogo entre o Brasil e a Polônia nas áreas de Ciências Humanas através de organização de simpósios e seminários com a participação de pesquisadores brasileiros e poloneses; c) Promover e elaborar traduções das obras literárias e ensaísticas polonesas; d) Desenvolver pesquisas relacionadas com a cultura polonesa e relações entre a Polônia e o Brasil; e) Organizar conferências e seminários dos pesquisadores e escritores poloneses na UnB, f) Cooperar com as universidades polonesas e a Embaixada da Polônia no Brasil nos projetos de intercâmbio científico e cultural, g) Colaborar com os pesquisadores das outras Universidades brasileiras interessados no desenvolvimento dos projetos relacionados com a cultura polonesa ou relações Polônia-Brasil. Pode-se perceber, que o processo de disciplinarização de estudos eslavos através do polonês na UnB passa pela criação de condições para o desenvolvimento do ensino da língua e cultura, mas também de diálogos, pesquisas, traduções, eventos, cooperação acadêmica nacional e internacional.

Ou seja, nesse mais recente curso de uma língua eslava, percebemos uma proposta de "desorientalização" sob o nome de um "um dos maiores poetas e dramaturgos poloneses, também pintor e escultor, é para a cultura polonesa uma referência de pensamento que reconhece e valoriza a linhagem multicultural da Polônia e da Europa" (CÁTEDRA CYPRIAN NORWID, sem página). Usa-se o nome de Cyprian Norwind para vincular a cultura polonesa ao multiculturalismo polonês e também à Europa, já pressupondo essa característica ao continente inteiro. Cabe ressaltar que esse curso é complementar aos outros cursos de línguas, e ambos ainda permanecem do nível de graduação com uma formação mais voltada à tradução literária, embora o curso da UnB atualmente conte com somente 3 semestres no sistema de leitorado com professores nativos, enquanto o da UFPR está com toda a grade de 8 semestres, isto é, períodos no bacharelado e na licenciatura. Cabe dizer que ambos cursos colaboram institucionalmente, criando um vínculo mais efetivo no plano de ensino e visitas acadêmicas.

A essa proposta se aproxima uma outra cujo nome indica uma abrangência de fato maior. O SLAV - Núcleo de estudos em eslavística surge em junho de 2017 na Universidade Federal do Rio de Janeiro, mas com a parceria com a Universidade Federal Fluminense, abrindo um espaço para reflexão, divulgação e pesquisa na área de estudos eslavos no estado do Rio de Janeiro. O núcleo abrange a área de Letras e Ciências Humanas, relacionando-os ao campo geral da Eslavística para a o qual propõe pesquisa, atividades de extensão, tradução e divulgação da pesquisa científica, segundo a apresentação que consta no seu sítio na internet. O trabalho desse núcleo se inicia com o $1^{\circ}$ Encontro do SLAV que nas palavras dos organizadores "representa o marco de criação do núcleo, ao 
mesmo tempo em que se rememoram os cem anos da Revolução Russa cujo impacto no mundo e, principalmente, nos países de cultura eslava, se faz sentir até a atualidade, em maior ou menor grau, nas diversas esferas da sociedade" (SLAV, 1 a Circular), novamente se referindo a Rússia e a revolução que houve em 1917. Outra frente de atuação é a própria revista SLOVO que iniciou as suas publicações no ano seguinte à sua criação.

$\mathrm{Na}$ Universidade Federal Fluminense existe também o Centro de Estudos Russos - CER que tem como objetivo "os estudos da língua, da cultura e de temas russos entre pesquisadores e estudantes de graduação e pós-graduação brasileiros" (CER, apresentação), mas também se propõe a facilitar intercâmbios de estudiosos do tema na América Latina e no resto do mundo. Conta com 40 pesquisadores nacionais e internacionais e está vinculado ao Programa de pós-graduação em História da UFF, o que representa uma diferença com relação às outras entidades mencionadas que estão normalmente mais dentro da área de Letras. Encontramos também o Núcleo de Estudos Russos da Universidade de Brasília cuja proposta de atuação não fica evidente no site. Mais um polo universitário é o "Laboratório de Estudos Russos" (LERUSS), aberto em 2011, como parte do convênio da USP com a fundação governamental russa "Rússkiy Mir" (Mundo Russo), o que o torna mais um exemplo de colaboração de universidades brasileiras com instituições eslavas em prol de estreitamento de relações bilaterais, como constata Pilz: "Além de apoio financeiro e doação de materiais didáticos, as atividades da fundação incluem organizar e promover conferências, congressos e seminários acadêmicos e incentivar atividades artísticas e culturais, como mostras de cinema, exposições e oficinas literárias" (2012, sem página).

NoParaná, desde 2001, atua o Núcleo de Estudos Eslavos(NEES) da UNICENTRO, como parte do Programa de Extensão Permanente desenvolvido na Unicentro, Campus de Irati, com uma equipe interdisciplinar formada por professores e acadêmicos. A abrangência é bastante local (municípios de Irati, Prudentópolis, Ivaí, Rio Azul, Mallet e Rebouças), pois "busca dar visibilidade à cultura eslava, fazendo levantamento dos aspectos culturais de povos eslavos que imigraram para a região centro-sul do Paraná" (COSTA; CHICOSKI; GARCIA; GARTNER; KUTZMY; KROIN; LOREGIANPENKAL; SANTOS; SILVA; SZYMCZAK; SOCHINSKI, 2013, p. 1). O destaque desse núcleo é o "Mapeamento do Patrimônio Cultural Eslavo no Sul do Paraná" que recebe contribuições de grupos de pesquisa "Língua, História e Literatura Ucraniana", "Língua, imigração e identidade" e "Estudos em História Cultural". Ele consiste em saídas de campo da equipe do NEES para observar as práticas culturais e também fortalecer os agentes culturais locais. É importante destacar de que, o que motivou a criação e as ações do NEES, foi o fato de existir uma presença significativa de cultura polonesa e ucraniana, 
bem como de falantes destas línguas que podemos chamar de euro-brasileiras. Estas suas características linguístico-culturais são apontadas pelas pesquisas feitas na Unicentro e no Núcleo nas diversas publicações promovidas, tais como: Campigoto e Chicoski (2013) em que são exploradas as múltiplas relações entre o Brasil e a Ucrânia para as quais as comunidades de imigração deram a sua contribuição; Costa e Loregian-Penkal (2015) que fazem justamente a descrição das especificidades do que chamam da fala eslava na região abrangida pela Universidade; e Gärtner e Loregian-Penkal (2015) que trazem uma discussões e diálogos interculturais sobre a imigração eslava na região, levando em consideração as atividades de extensão e pesquisa. E nesse sentido, pode se concluir que a sua singularidade de criação e funcionamento institucional reside no contexto social de vivência brasileira da cultura e de línguas eslavas. O próprio curso de ucraniano, iniciado como "Curso de aperfeiçoamento para professores de língua ucraniana" faz parte do programa e do núcleo, com objetivo de auxiliar aos professores da região que são falantes nativos, não têm a possibilidade de cursar uma habilitação universitária para exercer a docência. Além desse curso, o Núcleo apoio o atual curso de Polonês no Centro de Línguas da UNICENTRO aberto aos acadêmicos e à comunidade (externa), inclusive com atividades complementares que estabelecem diálogos com outras instituições do Brasil e com as da própria Polônia.

Grupo de pesquisa em estudos eslavos é mais um elemento integrante do Núcleo, ajudando na coleta e análise do patrimônio material e imaterial eslavo. Apresenta uma diversidade de linhas de pesquisa que não abrangem somente a língua e cultura, como segue: Aspectos socioculturais da Matemática; Cultura, memória e identidade; Literaturas de Língua Eslava; Políticas linguísticas e culturais e Questões de Bilinguismo. Nesse sentido, o mapeamento abrange vários aspectos da identidade eslava para além da língua, atuando em conjunto também com os programas de pós-graduação em História, Educação e Letras da UNICENTRO, especificamente com a linha de pesquisa "Educação, cultura e diversidade" do mestrado em Educação no qual alguns docentes do NEES atuam. E por fim, temos que destacar que o Núcleo organiza o Simpósio Internacional de Estudos Eslavos que teve cinco edições e que reúne pesquisadores e agentes culturais ligados ao mundo eslavo em terras brasileiras e europeias e também o Concurso Internacional de Contos Eslavos Baika que teve a sua segunda edição em 2019, promovendo, através de um gênero literário chamado Baika, a produção de conhecimento e relações eslavas multilaterais.

Explorando mais as produções textuais como locais de constituição do campo de estudos eslavos, podemos mencionar mais duas publicações que, na nossa visão, 
representam propostas constitutivas dessa área. Entre 1986 e 1990 foram publicados boletins mensais da revista chamada "Aproximações: Europa de Leste em Língua Portuguesa" que atualmente conta com 4 publicações chamadas Suplementos. O responsável pela revista é o Henryk Siewierski que veio ao Brasil em 1986 a convite da Fundação Pró-Memória para trabalhar no projeto de pesquisa que se relacionava com as comunidades eslavas do Sul do Brasil. A “Aproximações" em si nasce durante a estadia de Siewierski na Universidade de Lisboa, mas no Brasil recebe vários novos colaboradores e público que permitiu que fossem publicados diversos gêneros textuais (poesia, ensaios e comentários, conversas, prosa) autorais ou traduzidos sobre os países do Leste Europeu. O idealizador da revista menciona que "na seleção dos textos não o que decidia não eram as opções políticas, a opção que houve era pelas aproximações no amplo sentido da palavra" (SIEWIERSKI, 2011, p. 2). Podemos concluir que essa foi uma estratégia de aproximar o mundo eslavo e lusófono em uma época em que a divisão binária do mundo entre o Ocidente e Leste ainda era institucional e política, mas para a qual carecem estudos e análises mais aprofundadas que ofereceriam novas informações para a descrição dos estudos eslavas daquele momento.

E duas décadas mais tarde, em 2020, foi publicado um artigo acadêmico de Mendes, intitulado "A pesquisa das línguas eslavas no cenário da diversidade linguística na região Sul Brasil”" em que a autora levanta estudos descritivos da área de Linguística da imigração eslava na região meridional brasileira. Segundo ela:

constitui um dos focos de análise deste artigo o levantamento de documentos escritos, teses, dissertações e artigos produzido sobre essas línguas eslavas. O objetivo é abstrair sinteticamente os principais resultados desses estudos, identificando aí a necessidade de novas perspectivas teóricas, para compreender o contexto das línguas eslavas no atual cenário brasileiro. (2020, p. 2)

Fica claro o cunho exploratório e descritivo dessa pesquisa que, apesar de enfocar mais a produção de uma determinada área de conhecimento, traz uma preocupação em estudar línguas eslavas, mesmo que dedicando mais atenção ao polonês. Difere da primeira publicação pelo fato de não ser um lugar de recepção de múltiplas produções sobre o mundo eslavo, mas sim de mapeamento daquelas que dizem respeito a uma região e uma área de conhecimento. É um estudo sobre a produção de conhecimento em estudos eslavos, enquanto a revista Aproximações era um espaço de estímulo e divulgação de textos sobre o Leste Europeu, que abrange os países eslavos, e outros não-eslavos lá presentes. No entanto, ambas contribuem para o desocultamento do mundo eslavo no 
Brasil, cada uma de um modo, e nós as qualificamos como exemplos ou possibilidades de um espaço que mereceria estudos analíticos mais atentos para entendermos como foram se configurando os estudos eslavos no Brasil.

Como este artigo é justamente o resultado de um estudo exploratório e descritivo, estamos cientes que devem existir grupos/cursos/núcleos/centros e outras entidades que tratam o mundo eslavo e nós não constam nesse levantamento. Esse é o primeiro texto que apresenta um mapeamento que necessariamente terá que ser atualizado constantemente, uma vez que as etnias eslavas, e consequentemente, as suas entidades/instituições passam por um constante processo de ocultamento que dificulta a abordagem do processo de disciplinarização desta área.

Estudando o tema, encontramos na Proposta do extinto Programa de pós-graduação em Literatura e Cultura Russa a proposta intitulada "Iniciativa Ibero-Americana de Estudos da Rússia, do Mundo Eslavo e do Leste Europeu" que seria a mais abrangente de todas aqui colocadas. Resultado da articulação desse Programa com o Núcleo de Estudos Contemporâneos (NEC), da Universidade Federal Fluminense (UFF), em conjunto com a Cátedra de História da Universidade de Buenos Aires (Argentina) em 2007, a Iniciativa teria como objetivo:

estimular os estudos de ciências sociais, história, literatura, cultura, arte e língua da Rússia entre pesquisadores e estudantes de graduação e pós-graduação da América Latina e da Península Ibérica. Dadas as especificidades dos objetos de estudo, o Centro abre-se, em particular, para o diálogo com os estudos sobre o Leste Europeu e a Eurásia. Visa a promover intercâmbios, seminários e congressos entre tais pesquisadores e estudantes, e também o intercâmbio entre eles e outros pesquisadores e estudantes de temas russos em todo o mundo, e admite, como participantes, núcleos e grupos de estudos, assim como pesquisadores individuais de qualquer país do mundo, capazes de apresentar os resultados dos seus estudos em português ou espanhol (UNIVERSIDADE DE SÃO PAULO, 2009, p. 12-13).

Nota-se uma certa visão transnacional da iniciativa que, apesar de baseada na Rússia, abre-se para o Leste Europeu e Eurásia e que receberia indivíduos, instituições e coletivos de "qualquer país do mundo", porém desde que conseguissem se expressar em português ou espanhol. Pelo seu nome é compreensível que essas línguas sejam a base do diálogo e que a abrangência perpasse a Rússia, o mundo eslavo e o Leste Europeu, representando três espaços onde os pesquisadores poderão se inserir. Mesmo assim, chama-nos a atenção a separação da Rússia dos demais eslavos e da inserção do 
Leste Europeu como único denominador próximo dos eslavos, indicando novamente uma percepção que poderia ocasionar na orientalização da área de estudos eslavos.

Essa propostaérelativamente recente, porémnão foi possível encontrardocumentos, publicações ou registros públicos e/ou oficiais da sua atuação atual, um fenômeno que novamente nos leva ao questionamento dos porquês do seu ocultamento. Uma situação parecida acontece com a Sociedade Brasileira de Eslavística que é mencionada nos anos 1980 e começo dos 1990, para a qual não foi possível encontrar informações em publicações (de divulgação), nem em site ou qualquer outro meio. O único lugar em que encontramos mais dados é de Millarch (1986) no seu texto para o almanaque do jornal Estado do Paraná. Mencionam-se as falas dadas no Encontro sobre plurilinguísmo com temáticas como "análise das línguas eslavas, bilinguismo e contribuição da eslavística para a pesquisa linguística" (MILLARCH, 1986, p. 3), afirmando as potencialidades que as universidades onde há mais eslavos, focando no Paraná, poderão ter no contexto (inter) nacional. Novamente resta a pergunta sobre a não permanência de tais instituições e da inexistência de uma memória coletiva e institucional capaz de mantê-las mais próximas dos estudiosos das áreas que poderão aproveitar da sua experiência para criar novas entidades com mais êxito.

Com esses dois exemplos, mesmo que não totalmente positivos, terminamos o nosso levantamento inicial de estudos eslavos no Brasil que nos parece bastante promissor e não tão pequeno, embora sejam muitas as lacunas historiográficas do que já foi feito nessa área, devido ao mencionado processo de ocultamento étnico e institucional. Consideramos, portanto, fazer algumas pontuações e indicações de possíveis encaminhamentos para melhorarmos a situação geral dessa área de estudos no país.

\section{CONSIDERAÇÕES FINAIS}

Neste artigo apresentamos uma parte da pesquisa de pós-doutoramento em que oferecemos um estado da arte sobre os estudos eslavos por meio do estudo exploratório e descritivo que contribuiu para que pudéssemos iniciar um processo de disciplinarização desse campo científico. Portanto, abordamos principalmente a área acadêmica/ universitária brasileira com os cursos de (pós)graduação, polos/centros de pesquisa, divulgação e colaboração, bem como algumas das iniciativas (inter)nacionais, terminando com as publicações onde encontramos propostas constitutivas de estudos eslavos. Em se tratando de um trabalho exploratório que reconhece a lacunaridade como parte inevitável (principalmente por conta dos efeitos de ocultamento mencionados) e, principalmente, 
necessária para futuras produções de conhecimento que, por ventura, poderão surgir a partir de um diálogo com o que foi apresentado aqui. Esperamos que ainda possa ser feita uma publicação maior em que cada uma das instituições e entidades citadas pudesse trazer mais informações sobre o seu histórico e funcionamento.

Para tratar de um trabalho de localização e entendimento da constituição institucional desse campo, privilegiamos mais os agentes e suas articulações, reconhecendo que numa próxima publicação poderia ser realizado um estudo mais analítico de ideias e tendências referentes à produção escrita. Pensando nisso, notamos que em muitos casos determinadas línguas eslavas, nomeadamente o russo, ficam mais vinculados a uma noção de colaboração mais bilateral e de pesquisa literária e de tradução, enquanto no caso do polonês e ucraniano percebemos uma presença maior de aspectos locais e de estudos dos patrimônios criados por suas comunidades no Brasil, apesar de a comunidade polonesa contar com o apoio das instituições do país de origem na criação de cursos, cátedras e institutos universitários.

Podemos concluir que o caminho da afirmação do polonês e do russo no ambiente universitário por meio de cursos de graduação e pós-graduação se deu de um modo diferente, em momentos históricos diferentes. O russo inicia o seu reconhecimento institucional acadêmico nos anos 1960, enquanto o polonês vê isso somente na primeira década dos anos 2000. Apesar de os espaços de formação no nível de graduação sejam importantes para que se possa criar conhecimento e reflexão sobre o mundo eslavo e que os docentes das instituições estejam orientando pesquisas nesse sentido individualmente ou em algum programa de pós-graduação (não)específico, não se houve a afirmação de uma proposta mais ampla, apesar de terem sido criadas duas propostas, uma nacional Sociedade Brasileira de Eslavística e outra internacional - Iniciativa Ibero-Americana de Estudos da Rússia, do Mundo Eslavo e do Leste Europeu. Pelo que observamos, ambas tinham uma abrangência ampla de temas e possíveis participantes, mas não foi possível encontrar produções ou eventos disponíveis publicamente que resultassem em uma socialização ou divulgação dos seus resultados de modo a criar uma memória coletiva institucional presente.

Entendemos igualmente que as línguas costumam ser inseridas em diversos contextos, de línguas orientais ou centrais, ou mesmo clássicas, dependendo da época da criação do curso ou da instituição e da proposta subjacente ao seu funcionamento. Muitos cursos são acompanhados de criação de núcleos ou centros de estudos que, por sua vez, servem como local de encontro de diversos pesquisadores, vindos das mais variadas áreas de conhecimento, tais como o SLAV, o CER, o LERUSS, o NEES. Analisamos 
brevemente alguns dos discursos presentes nestes espaços, os quais nos ajudarão a entender como o curso, entidades e a área se inserem em determinadas perspectivas, sendo elas orientalistas, ocidentais, regionais, étnico-nacionais, científicas etc. Em uma outra publicação seria necessário olhar para os cursos livres de idiomas espalhados pelo país tanto os que pertencem àlguma instituição de ensino superior como aqueles que não têm esse vínculo, analisando seus currículos, projetos político pedagógicos etc.

Também seria importante adentrar na análise dos próprios cursos e suas disciplinas, algo que foi empreendido por Mendes (2020) no caso das línguas eslavas do Sul do Brasil, para sabermos as bibliografias utilizadas, bem como as metodologias as caracterizam, pois consideramos que devam existir diferenças consideráveis entre o modo como as línguas e culturas eslavas são ensinadas no Brasil. Isso é especialmente válido se olharmos para as comunidades de descendentes dos grupos eslavos que se radicaram no país, criando, ao longo do tempo, comunidades de fala singulares, abrindo espaço para o surgimento de novas línguas que fazem parte do cenário plurilinguístico nacional e global. Um melhor entendimento dessas línguas e sua relação com aquelas no mundo eslavo originário possibilitaria a criação de políticas linguísticas de sua incorporação nos currículos escolares, administração pública, atividades culturais oficiais e muitos outros lugares que dariam uma nova vida para a área. Lembramos que outros grupos linguísticos, por exemplo os germânicos com o Hunsrückisch e Pomerano e os italianos com o Talian, ou ainda os indígenas contam com cidades onde são cooficializados, isto é, reconhecidos como línguas legítimas ao lado do português, resultado de estudos prolongados sobre a sua presença em determinado território.

Embora tenhamos abordado algumas tendências em pesquisa, identificando um predomínio de estudos tradutológicos no caso da língua russa e estudos patrimoniais e culturais no caso de línguas polonesa e ucraniana, não adentramos mais detalhadamente na produção acadêmica feita pelos docentes e discentes das universidades brasileiras. Um próximo estudo poderia consistir em identificar as tendências, ideologias, históricos, conceitos e propostas presentes nos trabalhos acadêmicos, definindo as qualidades da produção científica sobre o tema do eslavo, junto com a criação de um espaço centralizador (repositório) onde estariam presentes as dissertações, teses e outros trabalhos menores que agora estão pulverizados em diversas plataformas.

Ainda tocando em futuras possibilidades de pesquisa, mencionamos somente alguns eventos que deram lugar a criação de grupos de pesquisa ou entidades, mas cuja existência ainda deve ser melhor evidenciada pelo fato de existiram muitos eventos acadêmicos: simpósios, ciclos, seminários, congressos em que se discutem assuntos tocantes ao 
mundo eslavo. Esse mapeamento por sua vez ajudaria aos futuros estudiosos conhecerem os espaços de apresentação e discussão, facilitando o acesso ao conhecimento criado no âmbito acadêmico e realização de contatos frutíferos para o desenvolvimento de novos projetos e frentes de atuação. Um tal projeto poderia ser um projeto de (pós)graduação interinstitucional de Estudos Eslavos que ajudaria a potencializar a já existente e ainda isolada produção científica, cultural, educacional dos profissionais que se encontram em diversas universidades e institutos e que sozinhos teriam dificuldades de sustentar uma linha ou um programa de (pós)graduação.

Acredita-se que, se todas essas novas frentes que recebessem uma atenção mais direcionada e bem preparada, passariam a receber um maior reconhecimento do trabalho feito nesse campo de estudos, dando mais visibilidade à comunidade eslava, desocultando a sua presença e contribuição. Igualmente conseguiriam criar condições para um melhor diálogo com os respectivos países que fazem parte dela. Saber o que acontece internamente, auxiliaria na procura de colaborações e parcerias com os países eslavos em questão, mas também com outros países não-eslavos onde existem comunidades de imigrantes, começando por aqueles que estão na América Latina. 


\section{REFERÊNCIAS:}

BARBOSA, H. G. A pós-graduação na Faculdade de Letras. Revista Interfaces, Rio de Janeiro, n. 10, p. 25-44, 2007.

BERNARDINI, A. Língua e Literatura Russa. Estudos Avançados, São Paulo, v. 8, n. 22, p. 467-470, 1994.

CAMPIGOTO, J. A.; CHICOSKI, R. (Orgs.) Brasil-Ucrânia: Linguagem, Cultura e Identidade. Jundaí: Paço Editorial, 2013.

COSTA, L. T. e LOREGIAN-PENKAL, L. A coleta de dados do banco VARLINFE variação linguística de fala eslava: peculiaridades e características. Revista Conexão $U E P G$, Ponta Grossa, v. 11, n. 1, p. 100-110, 2015.

COSTA, L. T.; CHICOSKI, R.; GARCIA, C. R.; GARTNER, M.; KUTZMY, S. L.; KROIN, V.; LOREGIAN-PENKAL, L.; SANTOS, C. F. R.; SILVA, E. S.; SZYMCZAK, P. C.; SOCHINSKI, L. O mapeamento do patrimônio cultural eslavo do Sul do Paraná. In: SEURS - SEMINÁRIO DE EXTENSÃO UNIVERSITÁRIA DA REGIÃO SUL, 31., 2013, Florianópolis. Anais... Florianópolis: Repositório Institucional da UFSC, 2014. Disponível em: <https://repositorio.ufsc.br/bitstream/handle/123456789/117378/ Cultura \%20-\%200\%20MAPEAMENTO\%20DO\%20PATRIM\%c3\%94NIO\%20 CULTURAL\%20ESLAVO\%20DO\%20SUL\%20DO\%20PARAN\%c3\%81\%20 $\% 281 \% 29$.pdf?sequence=1\&isAllowed=y>. Acesso em 21 jun. 2020.

CAMARGO, K; PUH, M. "Ver o invisível": patrimônio da imigração croata em São Paulo. Revista de Estudos Interdisciplinares, Rio de Janeiro, v. 2, n. 2, p. 24-43, mar./abr. 2020.

CÁTEDRA CYPRIAN NORWID. UNB. Endereço eletrônico. Disponível em: $<$ http://catedranorwid.unb.br/objetivos $>$. Acesso em 21 jun.2020.

CENTRO DE ESTUDOS RUSSOS. UFRJ. Disponível em: $<$ https://www.historia.uff.br/cer/>. Acesso em 21 nov. 2018.

DECOL, R. D. Uma história oculta: a imigração dos países da Europa do Centro-Leste para o Brasil. In: ENCONTRO NACIONAL DE ESTUDOS POPULACIONAIS, 12. 2000, Campinas. Anais eletrônicos... Campinas: PUC Campinas, 2000. Disponível em: $<$ http://www.abep.nepo.unicamp.br/docs/anais/pdf/2000/Todos/migt22_1.pdf $>$. Acesso em 02 jul. 2020. 
DINIZ, B. Línguas Orientais: linhas de pesquisa. Estudos avançados, São Paulo, v. 8, n. 22, p. 471-472, 1994.

ESCOBAR, A. Mundos y conocimientos de otro modo: el programa de investigación modernidad/colonialidad latinoamericano. Tabula Rasa [online], Bogotá, n. 1, p. 58-86, 2003.

GÄRTNER, M.; LOREGIAN-PENKAL, L. (Orgs.) Diálogos interculturais: extensão e pesquisa em contextos de imigração eslava. São Paulo: Todas as Musas, 2016.

GERHARDT, T.E.; SILVEIRA, D.T. Métodos de pesquisa. Porto Alegre: Editora da UFRGS, 2009.

GIL, A. C. Métodos e técnicas de pesquisa social. São Paulo: Atlas, 2008.

GUIMARÃES, E. (Org.). Produção e circulação do conhecimento. Política, ciência, divulgação. Campinas: Pontes \& CNPQ/PRONEX \& NJC, 2003. p. 193-207.

MALCZEWSKI, Z. O ensino da língua polonesa no Brasil: da escola dos colonos poloneses aos cursos de língua e literatura polonesa em universidades federais brasileiras. Polonicus - Revista de reflexão Brasil-Polonia, Curitiba, sem data. Disponível em: $<$ https://www.polonicus.com.br/site/biblioteca_interna.php?cod=139>. Acesso em 02 jul. 2020.

MARIANI, Bethania; MEDEIROS, Vanise. Disciplinarização dos estudos em Análise de Discurso. Revista Gragoatá, Instituto de Letras, Universidade Federal Fluminense, n. 34, p. $15-25,1^{\circ}$ sem. 2013.

MENDES. M.E. I. A pesquisa das línguas eslavas no cenário da diversidade linguística na região Sul Brasil. CadIL - Cadernos do Instituto de Letras, Porto Alegre, n. 59, p. 271290 , out.2019.

MILlARCH, A. Eslavística, o debate na Sociedade Brasileira Para o Progresso da Ciência. Estado do Paraná. Curitiba, 1986, p.3.

NÚCLEO DE ESTUDOS ESLAVOS EM ESLAVÍSTICA. Ia Circular. 26.06, 2017. Disponível em: $<$ https://nucleoslav.blogspot.com/p/1-circular.html>. Acesso em 02 jul. 2020.

PILZ, V. Fundação Russkiy Mir completa um ano de atividades no Brasil. Gazeta Russa, Moscou, 17 nov. 2012. Disponível em: <https://br.rbth.com/articles/2012/11/17/ fundacao_russkiy_mir_completa_um_ano_de_atividades_no_brasil_16483>.Acesso em 02 jul. 2020. 
PUH, M. "Tudo junto e misturado?": as contribuições e os limites do multiculturalismo no ensino de línguas. Revista El Toldo de Astier: propuestas y estudios sobre enseñanza de la lengua y la literatura, La Plata, Universidad Nacional de La Plata, ano 11, n. 20-21, p. 415-432, 2020.

RENK, V. E. Aprendi a falar português na escola! O processo de nacionalização das escolas étnicas polonesas e ucranianas no Paraná. 242 f. Tese (Doutorado em Educação) - Setor de Educação, Universidade Federal do Paraná, Curitiba, 2009.

SIEWIERSKI, H. Opção pelas Aproximações. Tradução em Revista, Rio de Janeiro, n. 10, 2011, p. 1-11. Disponível em: <https://www.maxwell.vrac.puc-rio.br/17851/17851. PDFXXvmi=>. Acesso em 02 jul. 2020. Entrevista concedida a João Vianney Cavalcanti Nuto.

TRIVIÑOS, A. N. S. Três enfoques na pesquisa em ciências sociais: o positivismo, a fenomenologia e o marxismo. In: TRIVIÑOS, A. N. S. Introdução à pesquisa em ciências sociais. São Paulo: Atlas, 1987. p. 31-79.

UNIVERSIDADE FEDERAL DO PARANÁ. Projeto Político-Pedagógico das novas habilitações do curso de letras: letras japonês e letras polonês-modalidades licenciatura e bacharelado. Curitiba, 2007. Disponível em: <http://www.humanas.ufpr.br/portal/ letrasgraduacao/files/2014/08/PROJETO-POL\%C3\%8DTICO-hbiita\%C3\%A7oesJAPONES-e-POLONES.pdf>. Acesso em 02 jul. 2020.

UNIVERSIDADE FEDERAL DO PARANÁ. Projeto pedagógico do curso de licenciatura em letras português e polonês. Curitiba, 2019. Disponível em: $<$ http://www.humanas.ufpr.br/portal/depac/files/2020/06/PPC-Lic-Port-Pol.pdf $>$. Acesso em 16 ago. 2020.

UNIVERSIDADE DE SÃO PAULO. Proposta Literaturas Estrangeiras Modernas Programa Literatura e Cultura Russa 33002010184P-3. São Paulo, 2008. Disponível em: $<$ http://conteudoweb.capes.gov.br/conteudoweb/VisualizadorServlet?nome=2008/33002 010/041/2008_041_33002010184P3_Proposta.pdf\&aplicacao=cadernoavaliacao $>$. Acesso em 02 jul. 2020. 